\title{
Low Estrogen Exposure and/or Defective Estrogen Signaling Induces Disturbances in Glucose Uptake and Energy Expenditure
}

\section{Zsuzsanna Suba*}

National Institute of Oncology, Surgical and Molecular Tumor Pathology Centre, Hungary

\begin{abstract}
Correlations between estrogen signaling and human morbidity seems to be very unclear and difficult topic Nowadays, the opinions of scientists have been partially changed regarding "estrogen induced diseases", but the overwhelming literary data are still contradictory. Physiological estrogen levels in healthy premenopausal women supply protection against insulin resistance, hypertension, cardiovascular diseases and malignancies as compared with men of the same age. However, after menopause a decreased ovarian estrogen synthesis will rapidly deteriorate the glucose sensitivity and increases the prevalence of life threatening diseases. New findings on the functions of tissular estrogen receptors (ERs) indicate that estradiol plays important role in the maintenance of glucose homeostasis and energy expenditure. Diverse disorders associated with insulin resistance are usually well treatable by estradiol substitution both in pre- and postmenopausal women as well as in animal experiments. ERs seem to have balanced interplay in the maintenance of adaptation to the momentarily changing intra and extracellular stimuli. This equilibrium may be shattered in case of a defective estrogen supply or by the derangement of ER signaling pathways. Understanding the crosstalk and interplay between ERs illuminates the fact that there is no good or bad ER isoform, but they construe a complex system so as to achieve an ideal internal milieu. Considering the regulatory effects of ERs on food intake, insulin secretion, glucose uptake and metabolic processes, estrogen administration may be a therapeutic avenue to repair insulin sensitivity in patients with dysmetabolism and diabetes mellitus.
\end{abstract}

Keywords: Estrogen signaling; Insulin resistance; Metabolic syndrome; Type 2 diabetes; Infertility; Menopause

\section{Introduction}

A famous hypothesis of Reaven established a causal association between cellular insulin resistance and compensatory hyperinsulinemia, which were than regarded as basic disorders for several human diseases [1]. Earlier, cardiovascular lesions, hypertension, dyslipidemia, obesity and elevated fasting glucose level were attributed to be the complications of type 2 diabetes. Nevertheless, the sequence of these alterations was frequently inconsequent and contradictory. The new theory revealed that many divergent symptoms and findings all have a common soil; the defective glucose uptake of mammalian cells [2].

Actions of female sexual steroids are much wider than having crucial roles in female physiology and reproduction [3]. Physiological estrogen levels in healthy premenopausal women supply protection against insulin resistance, hypertension, cardiovascular diseases and malignancies as compared with men of the same age [4,5]. However, after menopause a decreased ovarian estrogen synthesis will rapidly deteriorate the glucose uptake and increases the prevalence of life threatening diseases.

New findings on functions of tissular estrogen receptors indicate that estradiol plays important role in the maintenance of glucose homeostasis and energy expenditure [6]. It beneficially modulates the expression of genes that are involved in insulin secretion, cellular insulin sensitivity and glucose uptake at different sites [6,7]. Nevertheless, there are conflicting data concerning estradiol action in women and its relation to glucose homeostasis and insulin sensitivity in pre- and postmenopausal cases.

Recent studies suppose that a functional imbalance between the signals of estrogen receptor (ER) isoforms and gene polymorphism of ERs may have important implications for the development of dysmetabolism, such as metabolic syndrome and type 2 diabetes
[8]. Moreover, hyperestrogenism is erroneously supposed to disrupt the glucose uptake in the adipose tissue mass in obese women and is presumed to contribute to insulin resistance and the associated comorbidities $[9,10]$.

Results of animal experiments support that estradiol administration improves the metabolic functions in insulin resistance and obesity $[11,12]$. Elevated estrogen level is advantageous against metabolic disorders and decreases the risk for associated diseases. In experimental animals, pregnancy analogue estradiol administration counteracts to the growth of chemically induced or transplanted malignant tumors [13-15]. Moreover, high dose estrogen administration as ovulation provocation and good hormonal equilibrium in multiparous women prove to be metabolically advantageous and exhibit anticancer capacities [16].

In human metabolic diseases the beneficial effects of estradiol treatment justify that ERs conduct advantageous intracellular signals if the estrogen supply is sufficient [17]. Conversely, in estrogen deficient states or in case of defective ER signals an increased prevalence of metabolic syndrome, type 2 diabetes and their comorbidities is characteristic [7].

The purpose of this study is to examine the real significance of estradiol supply in cellular metabolic functions. Experimental studies

*Corresponding author: Zsuzsanna Suba, National Institute of Oncology, Surgical and Molecular Tumor Pathology Centre, H-1122 Ráth György str. 7-9, Budapest, Hungary, Tel: 0036122486 00; Fax: 0036122486 20; E-mail: subazdr@gmail.com

Received June 15, 2013; Accepted July 22, 2013; Published July 28, 2013

Citation: Suba Z (2013) Low Estrogen Exposure and/or Defective Estrogen Signaling Induces Disturbances in Glucose Uptake and Energy Expenditure. J Diabetes Metab 4: 272. doi:10.4172/2155-6156.1000272

Copyright: (C) 2013 Suba Z. This is an open-access article distributed under the terms of the Creative Commons Attribution License, which permits unrestricted use, distribution, and reproduction in any medium, provided the original author and source are credited. 
on disabled ER knockout mice help to evaluate the unique and apparently controversial functions of each ER isoform. Nevertheless, understanding the crosstalk and interplay between them illuminates the fact that there is no good or bad ER isoform, but they construe a complex system so as to achieve an ideal internal milieu.

\section{Role of Estradiol and its Receptors in the Regulation of Cellular Glucose Uptake and Energy Homeostasis}

The metabolic state of the body is controlled by a central regulation of the brain through signals arriving from the pancreas, liver, adipose tissue, skeletal muscle, and gut [8]. A wide variety of these signals includes hormones (insulin, leptin, adiponectin, etc.), cytokines (TNF- $\alpha$, IL-6) and nutrients (glucose, free fatty acids, lipids).

Estrogens have pivotal effects on energy metabolism and glucose homeostasis [6]. Two receptor isoforms were identified; estrogen receptor alpha $(\mathrm{ER} \alpha)$ and estrogen receptor beta $(\mathrm{ER} \beta)$, which belong to the steroid-thyroid hormone nuclear receptor supergene family $[17,18]$.

The classic genomic mechanism of estrogen binding activates ERs in the nucleus and they act as transcriptional modulators in the promoter region of target genes. ERs can also regulate gene expression without direct binding to DNA through interaction with transcription factor proteins in the nucleus [3]. Estrogen action has also non-genomic signaling cascades through cell membrane associated ERs [19]. Finally, genomic and non-genomic pathways of estrogen receptor signaling converge on the target genes.

$E R \alpha$ and ER $\beta$ regulates in thorough interplay the metabolic processes, the cell growth and the cell proliferation of mammalian cells. They may oppose the activities of each-other eliciting sometimes quite opposite reactions in the presence of estradiol [20], which may be crucial for the dynamism of regulatory mechanisms.

Discovery of selective agonists for ER $\alpha$ and ER $\beta$ yielded new possibilities to research the specificity of estrogen receptors [21]. PPT, an ER $\alpha$ selective agonist provoked an increase in cell number nearly $50 \%$, while DPN, an ER $\beta$ selective ligand caused a decrease of $30 \%$. Selective activation of each receptor alone increased cell metabolism independently as either mitotic activity or cell growth require enhanced cellular metabolism. However, the simultaneous activation either by estradiol or by PPT-DPN combination produced equilibrium in metabolic activity.

Development of the three knockout mouse lines: estrogen receptor aand $\beta$ knockout (ER $\alpha \mathrm{KO}, \mathrm{ER} \beta \mathrm{KO}$ ) and aromatase enzyme knockout (ARKO) mice provided new opportunities for understanding the individual actions of estrogen receptor isoforms. ER $\alpha$ knockout mice exhibit insulin resistance, impaired glucose tolerance and obesity affecting both males and females [22]. Ovariectomy of insulin resistant ER $\alpha$ knockout mice (i.e. removal of the action of estradiol on ER $\beta$ ) improved glucose and insulin metabolism [23], suggesting that ER $\beta$ might have a diabetogenic, opposing action against ER $\alpha$. In the maintenance of normal glucose homeostasis ERa mainly enhances the capacity for glucose uptake, whereas ER $\beta$ exerts contraregulatory activity [6].

\section{Role of Estrogen Signaling in the Central Regulation of Metabolism and Energy Homeostasis}

The central nervous system may induce metabolic and behavioral changes by anorexigenic and orexigenic stimuli so as to maintain the serum glucose level and energy homeostasis [8]. The hypothalamic nuclei are pivotal regulators of food intake and energy expenditure by means of their estrogen receptors [24].

The main hypothalamic areas involved in feeding behavior are the arcuate nucleus (AN), the lateral hypothalamus (LH), the paraventricular nucleus (PVN), the ventromedial nucleus (VMN) and the dorsomedial nucleus (DMN) [25] (Figure 1). Both ERs have been identified in the AN, LH and DMN $[25,26]$. The PVN shows the highest expression of ER $\beta$ isoform [26], whereas VMN is mainly ER $\alpha$ regulated having important function in food intake inhibition [27]. In animal experiments, direct estrogen actions in the hypothalamus lead to anorexia. In ovariectomized mice, increase in food intake, body weight and abdominal fat mass are characteristic, which are reversible by estradiol administration [27].

Leptin is an adipocytokine secreted by adipose tissue in direct proportion to body fat mass. It has crucial role in the central regulation of metabolism and transfers catabolic signals to the hypothalamic nuclei to inhibit food intake and increase energy expenditure $[28,29]$. Estrogen modulates leptin synthesis and secretion via ER-dependent transcriptional mechanisms [30] and increases the leptin sensitivity of the brain [31]. Ovariectomy reduces leptin sensitivity and this effect can be reversed by estradiol substitution [32].

In rats and mice the ERa-selective agonist, PPT, rapidly results in a decrease in food intake [33], whereas silencing of ERa leads to hyperphagia, obesity, decreased glucose tolerance and reduced energy expenditure [34]. In ovariectomized rodents treatment with an ERaspecific ligand (PPT) resulted in an inhibition of eating and reduced body weight.

The exact role of ER $\beta$ in the central regulation of feeding is less known [8]. In ovariectomized rats, estradiol and ER $\beta$ anti-sense oligodeoxynucleotides (ODN) administered into the third ventricle in the brain reduced the inhibitory effect of estrogen on food intake [35] This result suggests that in some hypothalamic areas ER $\beta$ mediates the central anorexic effect of estradiol.

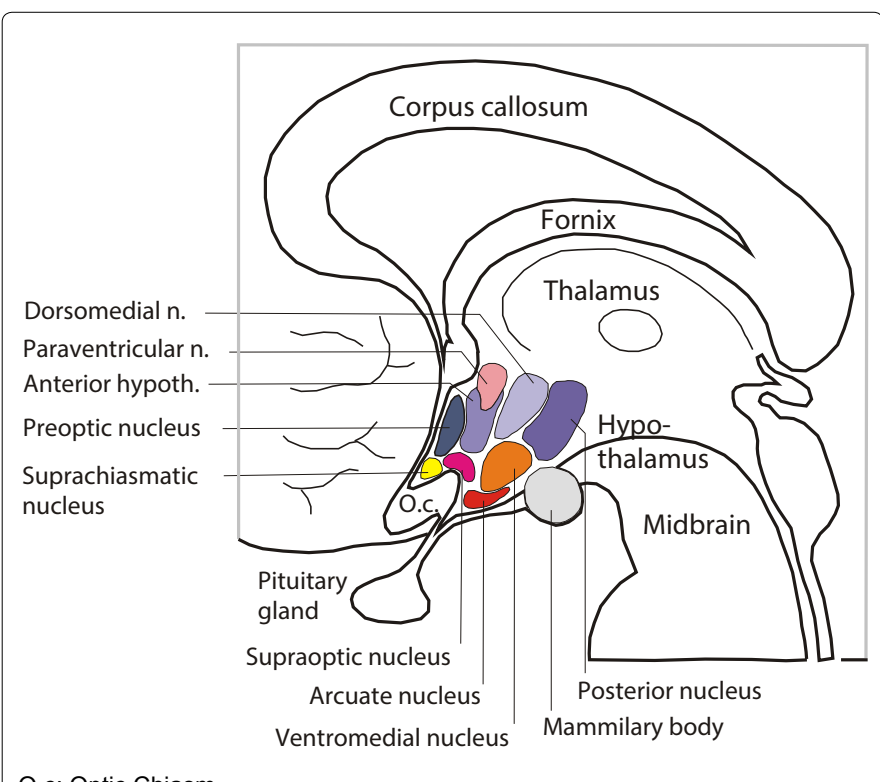

O.c: Optic Chiasm

Figure 1: Hypothalamic nuclei. Linkage between the central nervous system and the pituitary gland. 
The hypothalamus has a wide control over insulin, glucocorticoid and gonadal hormone functions, which have important role in defining insulin sensitivity and consequently in peripheral carbohydrate and lipid metabolism [36]. The ratio of male to female sexual hormone levels affects peripheral fat distribution attributed to a modulation of insulin sensitivity. Estrogen deficiency or defective estrogen signaling results in insulin resistance and an increase in the adipose tissue mass, preferentially in visceral location [37].

\section{Estrogen Receptor Actions on Pancreatic Islets and Insulin Production}

Estradiol and its receptors are key players in the physiology and insulin production capacity of the $\beta$ cells of pancreatic islets [38]. Estradiol administration is associated with pancreatic islet hypertrophy and increased insulin release from the $\beta$ cells in rats. Islet cells isolated from ovariectomized mice respond to glucose with a smaller insulin release than islet cells from intact mice. Estradiol replacement in ovariectomized mice normalizes the insulin response to glucose ingestion [6]. ER $\alpha$ activation promotes $\beta$-cell mass proliferation and insulin biosynthesis in diabetic and obese cases, whereas ER $\beta$ activation improves glucose stimulated insulin secretion [39].

After menopause, estrogen loss decreases the insulin secretion, which is transitorily compensated by its reduced elimination [40]. During postmenopausal hormone replacement therapy or contraceptive use estradiol improves insulin secretion, sensitivity and elimination.

Estrogen signaling seems to be essential for structural and functional $\beta$ cell adaptation, especially during high metabolic demand and insulin resistant periods [8]. Recognition of these correlations leads to novel therapies for $\beta$-cell related diseases as estrogen administration preserves functional $\beta$-cell mass in patients with diabetes mellitus.

\section{Estrogen Receptors and Energy Homeostasis in the Liver}

Liver function disturbances are in close correlation with insulin resistance, hyperglycemia and dyslipidemia. Estrogen plays a pivotal role in the regulation of hepatic glucose homeostasis. ERa is the predominant receptor isoform in human hepatocytes and ER $\alpha$ signal is essential for the glucose tolerance of the liver $[41,42]$.

Insulin modulates hepatic glucose uptake by the activation of glycogen synthase and glycogen phosphorylase leading to glucose storage as glycogen, whereas it may stimulate glycolysis through the activation of several hepatic enzymes [43].

PPT, a selective ERa agonist, improved glucose tolerance and insulin sensitivity in genetically obese mice suggesting that estradiol has antidiabetogenic impact via ERa [44]. In the liver of ERa knock out (ERaKO) mice, hepatic insulin resistance, increased glucose production and lipid synthesis as well as decreased lipid transport were observed [42]. By contrast ER $\beta$ might be diabetogenic as ER $\beta$ knock out $(\mathrm{ER} \beta \mathrm{KO})$ mice with increased body weight exhibited improved hepatic and muscular insulin sensitivity due to reduced accumulation of triglycerides [45].

Estradiol have pivotal interactions with growth hormone (GH)regulated endocrine (e.g., IGF-I), metabolic (e.g., lipid and glucose metabolism) and sex-differentiated (e.g., endo- and xenobiotic metabolism) functions in liver [45]. Estrogens modulate GH action at the level of pituitary $\mathrm{GH}$ secretion and have pivotal role in the regulation of GH activity, receptor expression and signaling as well [46].
Estrogen induced suppression of cytokine signaling negatively regulates GHR-Janus kinase (JAK)-2-signal transducer and activator of transcription (STAT)-5 signaling pathway [46,47]. Estrogen induced disruption of GHR-JAK2-STAT5 signaling may be associated with hepatic metabolic changes that include fatty liver, fibrosis, and hepatocellular carcinoma [48]. Complex interplay between GH and estrogen seemed to be disquieting because of the physiological roles of these hormones in mammals, and the widespread use of estrogenrelated compounds [45].

Conversely, $17 \beta$-estradiol administration could suppress tumor growth in mice with hepatocellular carcinoma [49]. Estradiol suppressed the alternative macrophage activation and tumor progression by keeping ER $\beta$ away from interacting with ATPase-coupling factor 6 , a part of ATPase, thus inhibiting the JAK1-STAT6 signaling pathway. This study introduced a novel mechanism for the estrogen suppression of male-predominant hepatocellular carcinoma.

$\mathrm{ERa}$ confers estradiol mediated protection of the liver from inflammatory injuries [50]. Ovariectomized mice were treated by IL-18 to induce hepatic inflammation and estradiol hampered the expression of cytokines in ER $\beta \mathrm{KO}$ but not in ER $\alpha \mathrm{KO}$ mice. Estrogen may suppress the production of hepatocyte growth factors and interleukin-6, which modulates the inflammatory environment of hepatocellular carcinoma in rats and inhibits metastatic spread [51].

Estradiol replacement in postmenopausal women increased HDL and decreased LDL, total cholesterol, lipoprotein, fasting insulin and glucose levels, exhibiting antidiabetogenic and antiatherogenic impacts [52]. Conversely, estrogen deficiency, such as antiestrogen (tamoxifen) therapy or ovariectomy resulted in atherogenic lipid profile and hepatic steatosis increasing the risk of metabolic syndrome and cardiovascular diseases [53].

\section{Estradiol Actions on the Energy Homeostasis of Skeletal Muscles}

Skeletal muscle mass is responsible for $75 \%$ of the insulin-mediated glucose uptake in the body and consequently, physical activity is in close correlation with insulin sensitivity [8].

Insulin receptors (IRs) help the active glucose transport through the double lipid layer of the cell membrane (Figure 2). IRs has outer a-subunits with binding sites for insulin and two transmembrane $\beta$-subunits. Insulin interaction with the external $\alpha$-subunits induces auto-phosphorylation of the $\beta$ subunits at multiple tyrosines resulting in an activation of signal transduction [54]. The phosphorylation cascade provokes translocation of glucose transporter (GLUT4) containing cytoplasmic vesicles to the cell membrane. GLUT4 anchored and incorporated into the cell membrane enables the facilitated diffusion of glucose from the extracellular space into the cell [55]. Alterations in this mechanism, such as insulin deficiency, disturbance in insulin signal transduction, GLUT4 expression and/or translocation result in insulin resistance.

Estradiol stimulates the phosphorylation of Akt, AMPK and the Akt substrate in soleus muscle [56]. Estradiol administration to insulin resistant rats or mice increases the insulin receptor substrate content and the concentration of the phosphorylated form of Akt in muscles, restoring the action of insulin [57].

ERs advantageously modulate insulin stimulated glucose uptake through the regulation of the tyrosine phosphorylation of insulin receptor protein [58]. ERs promote GLUT4 expression and 
intracellular translocation as well. Moreover, estradiol improves glucose homeostasis through the facilitation of GLUT4 incorporation into the cell membrane (Figure 2). By this way, estradiol treatment increases the GLUT4 content of the cell membrane [59]. In ovariectomized rats, the decreased amount of GLUT1 protein in the blood-brain barrier was increased after estradiol substitution [60].

Aromatase knockout (ARKO) mice with inactivation of the enzyme for estrogen synthesis, exhibit reduced glucose oxidation, increased adiposity and hyperinsulinemia both in males and females [61,62]. Glucose intolerance and insulin resistance can be reversed by estradiol administration even in male ARKO mice [63].

Skeletal muscle expresses both ERs, and in mice ER $\beta$ is the predominant isoform [8]. Treatment with the ERa selective agonist, PPT increased GLUT4 translocation to the cell membrane of L6 myoblasts, and when ER $\alpha$ was silenced the translocation decreased [64]. ERa knockout (ERaKO) mice are glucose intolerant and insulin resistant [22] as the absence of $\mathrm{ERa}$ involves a reduced glucose uptake in muscles [42]. ER $\beta$ is a repressor of GLUT4 expression and translocation. In ER $\beta \mathrm{KO}$ mice both glucose tolerance and insulin release remains normal or better than in wild type mice [42,44]. These data exhibit that a steadily balanced activation of both receptors may ensure the ideal glucose tolerance and energy expenditure.

During estrogen loss in the postmenopausal period, muscle strength exhibits a striking decline that can be reversed by hormone replacement therapy (HRT), suggesting that estrogens are important modulators of muscle physiology $[65,66]$.

Some authors have established that hyperestrogenism is also related to insulin resistance similarly, to estrogen deficiency [67]. In women with irregular menstrual cycles and gestational diabetes, hyperestrogenism was presumed to be a contributor to insulin resistance $[9,10]$. Nevertheless, today these pathologic insulin resistant states are attributed to hyperandrogenism and deficient estrogen synthesis rather than to estrogen excess $[7,16]$.

Taken together, estrogens increase insulin sensitivity, whereas an estrogen deficient milieu endangers the balanced glucose uptake and energy expenditure of skeletal muscles leading to insulin resistance [7].

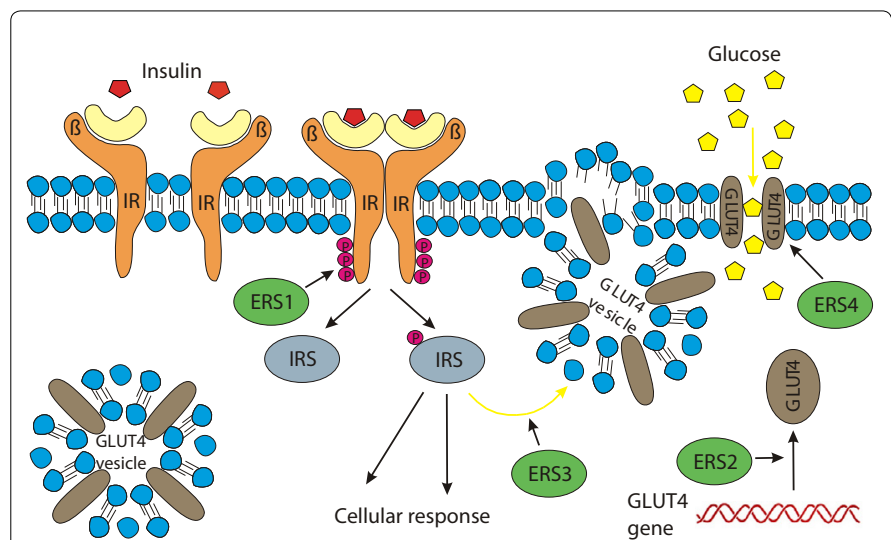

Figure 2: Insulin receptor (IR) activation and glucose uptake. Insulin binding to $\alpha$ subunits induces the phosphorylation $(P)$ of transmembrane $\beta$ subunits generating insulin receptor signal transduction (IRS). Glucose transporter (GLUT4) vesicle translocation to the cell membrane allows intramembranous incorporation of GLUT4 and it enables the facilitated diffusion of glucose into the cell. Estrogen receptor signal (ERS) regulates the phosphorylation of IR protein (ERS1), participates in GLUT4 expression (ERS2) and translocation (ERS3), as well as in the intramembranous incorporation of GLUT4 (ERS4).

\section{Role of Estrogen Receptors in the Energy Homeostasis of Adipose Tissue}

Fatty tissue participates in a variety of metabolic, endocrine and immunologic processes and interacts with CNS and peripheral organs by means of adipokine secretion. The size of the fatty tissue compartment clearly reflects the balance between whole-body energy intake and expenditure [68]. Increased adipose tissue in visceral location has been linked to a self-generating process of insulin resistance [16].

In rats, ovariectomy increased body weight, intra-abdominal fat mass, fasting glucose, insulin levels and insulin resistance. Estradiol substitution restored normoglycemia, increased the expression of adiponectin and decreased resistin expression resulting in improvement of insulin resistance [69].

In healthy premenopausal women, estradiol counteracts to the accumulation of visceral fat, and decreases the lipogenic activity of lipoprotein lipase in adipose tissue [34]. By contrast, irregular or long menstrual cycles in young women are associated with insulin resistance and predict occurrence of type 2 diabetes attributed to the defective estrogen synthesis [70,71]. Postmenopausal decreasing estradiol production, deepening insulin resistance and decreased lipid utilization result in visceral fat mass accumulation [72].

The presence of ER $\alpha$ and ER $\beta$ isoforms was confirmed in human adipocytes from both subcutaneous and intra-abdominal fat, with clear predominance of $E R \alpha$ [73]. Although the separated functions of the two ERs in adipose tissue may be studied on disabled ERaKO and ER $\beta K O$ mice, these results may hardly be extrapolated to human practice. The only clinical case was a 28 -year-old man with defective ERa who presented with glucose intolerance, hyperinsulinemia and obesity [74]. Hyperestrogenism in this patient seemed to be a contra-regulatory effect. Failure of his ERa signal leaded to premature coronary artery disease and decreased HDL cholesterol level [75].

In male mice deletion of ERa induces insulin resistance and progressive increase in adipose tissue with advancing age. In female ERaKO mice insulin resistance, increased adiposity, higher leptin and cholesterol levels and smaller LDL particles are characteristic [22].

Estradiol substitution in ovariectomized mice kept on highfat diet preserved glucose tolerance and insulin sensitivity [12] Studies on ER $\alpha$ and ER $\beta$ knockout mice suggest that ERa is the main regulator of GLUT4 expression in adipose tissue [8] and the two ER isoforms seem to have opposite functions on fat metabolism [23]. In human adipocytes GLUT4 abundance is highly correlated with insulin responsiveness. In polycystic ovarian syndrome (PCOS) cases with ovarian overproduction of testosterone and defective estrogen synthesis, insulin stimulated glucose uptake was reduced due to decreased amounts of GLUT4 on adipocyte membrane [76].

\section{Presumed Role of Gene Polymorphism in the Alterations of Estrogen Signaling and in the Development of Metabolic Syndrome}

Epidemiological and prospective studies suggest controversial associations between estrogen signaling and several aspects of the metabolic syndrome [8]. Rapid development of new methods for genetic investigations enabled scientists to analyze the polymorphism of the estrogen receptor a gene (ESR1) coding for ERa. Gene polymorphism may induce either enhancing or silencing of the signal transduction of ERs, yielding possibilities for the rational explanation of puzzling links among estrogen, metabolic disorders and the associated morbidities.

Of the many hypotheses trying to explain the health advantage of 
women over men, none has received more attention than the estrogen hypothesis [77,78]. Nevertheless, some of the large studies have indicated a lack of metabolic benefit and an early increase in CVD and breast cancer risk from the use of hormone replacement therapy in postmenopausal cases [79]. As a plausible possibility, genetic variations in estrogen mediated pathways emerged as contributors to inter-individual and sex-specific variation in health risk [80]. Gene polymorphisms of ESR1 and their correlations with each component of metabolic syndrome and insulin resistance associated comorbidities were thoroughly investigated but the results proved to be contradictory.

Apparently controversial results were published in relation to ESR1 polymorphism and the prevalence of myocardial infarct. In the Framingham Heart study, male carriers of the common ESR1 IVS1$397 \mathrm{~T}>\mathrm{C} \mathrm{C} / \mathrm{C}$ genotype, were found to have a substantial increase in the risk of myocardial infarction [81]. Conversely, in the Rotterdam study, postmenopausal female carriers of the ESR1 haplotype 1 (IVS1$397 \mathrm{~T}>\mathrm{C}^{\star} \mathrm{T}$ allele and IVS1-351 $\mathrm{A}>\mathrm{G}^{\star} \mathrm{A}$ allele), were shown to have an increased risk of myocardial infarct and ischemic heart disease, whereas in men an absence of this association was reported [82].

Further studies also demonstrated conflicting results. The presence of the IVS1-397T $>\mathrm{C}^{\star} \mathrm{C}$ allele was protective against the risk of in-stent restenosis [83]. In postmenopausal women with HRT use, homozygous for the C allele at the IVS1-397T $>C$ site, the severity of atherosclerosis was milder and less progressive [84]. By contrast, negative effects of the same allele have also been described; it was associated with risk of aortic valve sclerosis and coronary atherosclerosis at angiography in women [85]. Nevertheless, age distribution, body weight, HRT use and other factors of the examined population may thoroughly influence the CVD risk besides the ER genotype.

Associations of polymorphism in the estrogen receptor $\beta$ gene (ESR2) with recurrent spontaneous abortion were examined in the Chinese population. There were no significant differences in gene polymorphisms between women with full term pregnancy and with recurrent spontaneous abortion [86].

Correlations between genetic polymorphisms in the ESR1 gene and breast cancer risk are highly inconclusive. Pvull polymorphism was associated with a moderately increased risk, whereas, Xbal polymorphism was related to non-significantly elevated risk confined to older postmenopausal women in Shanghai [87]. Conversely, in a Korean study Pvull genotype distribution did not show any differences between breast cancer cases and controls, while the adjusted odds ratio for the Xbal allele containing genotypes was advantageously decreased $(\mathrm{OR}=0.4)$, particularly in postmenopausal cases [88]. These results suggest that even in genetic investigations, mainly postmenopausal state and ageing associated estrogen deficiency define the altered estrogen signaling leading to breast cancer [89]. Moreover, these studies cannot clarify the ligand binding strength and the negative or positive changes in the signaling pathways of estrogen attributed to gene polymorphism.

Although endometrial physiology is closely dependent on estrogen exposure, there were no significant associations between ERS1 gene polymorphisms and endometriosis in Japanese women [90]. Correlations between ESR1 polymorphism and endometrial cancer risk are also controversial. Some studies indicate that common genetic variants within ER cofactor genes are unlikely to play significant role in endometrial cancer risk in the European population [91]. In a further study the c.454-397C $\rightarrow$ T CC and c.454-351A $\rightarrow$ G GG genotypes were associated with a decreased risk for endometrial cancers [92].

In PCOS cases, Pvull and Xbal polymorphisms of ESR1, as well as Alul and Rsal polymorphisms of ESR2 were genotyped, and no difference was found in the distribution of these gene variants between patients and healthy controls [93]. Nevertheless, in PCOS women, carriers of TC and TT genotypes of Pvull polymorphism had lower fasting glucose to insulin ratio compared with carriers of CC genotype. These results suggest some associations of $\mathrm{ERa}$ polymorphisms with insulin resistance in PCOS.

Correlations between hormone replacement therapy (HRT) and mortality of women were examined to determine whether the risk of HRT associated mortality varies depending on the genetic variability of ERs [94]. These studies suggested that some women are genetically more vulnerable to the effects of HRT in terms of their estrogen receptor genotype.

\section{Lifelong Changes in the Sex Hormone Levels of Women and their Correlation with Insulin Resistance, Type-2 Diabetes and Obesity}

In premenopausal women, the equilibrium of sexual steroid synthesis defines somatic health and reproductive capacity, whereas symptom-free adaptation to the estrogen deficient environment is a prerequisite of postmenopausal health $[16,89]$. Changes in the sexual hormone equilibrium during women's lives strongly influence insulin sensitivity and the associated risk for type 2 diabetes and obesity (Table $1)$.

\section{Changes in sexual hormone levels and insulin sensitivity in puberty}

In puberty, the extreme somatic growth and explosion-like sexual development mean a great challenge for the metabolic and hormonal systems. In this period there is a higher risk for development of insulin resistance, particularly in overweight cases [16]. Recent results support that poor natural light exposure in puberty also mediates insulin resistance and hormonal alterations by excessive melatonin secretion [95].

In adolescent girls, the developing insulin resistance leads to abnormal ovarian sexual steroidgenesis as well, resulting in excessive androgen and defective estrogen production associated with menstrual irregularity and anovulatory cycles [96-98]. Hyperandrogenism and insulin resistance in adolescents are preserved into adulthood and result in defective fertility patterns and dysmetabolism at least until 30 years of age [99-101]. This prolonged hormonal and metabolic imbalance might be a defining, dangerous factor for adult metabolic syndrome, type 2 diabetes and their comorbidities.

\section{Correlations between changes in estrogen levels and insulin sensitivity in premenopausal women}

In premenopausal young women, defective estrogen synthesis is frequently associated with anovulation and infertility. Clinical signs of ovarian insufficiency are the long and/or irregular menstrual cycles [102,103]. These reproductive dysfunctions are related to hyperinsulinism and excessive androgen production.

Among premenopausal hormonal disorders with insulin resistance and fertility failure, the polycystic ovarian syndrome (PCOS) is the most prevalent, presumably caused by a large number of different genetic abnormalities [104]. PCOS may usually be manifested by menstrual disorders, anovulatory infertility, hirsutism and obesity or overweight. Nevertheless, polycystic ovaries are common findings in symptom-free cases with normal menstrual cycles as well; only the laboratory findings 


\begin{tabular}{|c|c|c|c|c|}
\hline Hormonal changes in the life periods of women & Estrogen level & Androgen level & Insulin resistance & Risk for type-2 diabetes and obesity \\
\hline \multicolumn{5}{|c|}{ Adolescence } \\
\hline menstrualdisorder & $\downarrow$ & $\uparrow$ & $\uparrow$ & $\uparrow$ \\
\hline anovulatory cycles & $\downarrow$ & $\uparrow$ & $\uparrow$ & $\uparrow$ \\
\hline \multicolumn{5}{|c|}{ Premenopausal women } \\
\hline anovulatory infertility & $\downarrow$ & $\uparrow$ & $\uparrow$ & $\uparrow$ \\
\hline nulliparity & $\downarrow$ & $\uparrow$ & $\uparrow$ & $\uparrow$ \\
\hline PCOS & $\downarrow$ & $\uparrow$ & $\uparrow$ & $\uparrow$ \\
\hline hyperprolactinemia & $\downarrow$ & $\uparrow$ & $\uparrow$ & $\uparrow$ \\
\hline antiestrogen treatment & $\downarrow$ & $\uparrow$ & $\uparrow$ & $\uparrow$ \\
\hline contraceptive use & $\uparrow$ & $\downarrow$ & $\downarrow$ & $\downarrow$ \\
\hline \multicolumn{5}{|c|}{ Postmenopausal women } \\
\hline HRT use & $\uparrow$ & $\downarrow$ & $\downarrow$ & $\downarrow$ \\
\hline non HRT use & $\downarrow$ & $\uparrow$ & $\uparrow$ & $\uparrow$ \\
\hline antiestrogen treatment & $\downarrow \downarrow$ & $\uparrow \uparrow$ & $\uparrow \uparrow$ & $\uparrow \uparrow$ \\
\hline hysterectomy & $\downarrow \downarrow$ & $\uparrow \uparrow$ & $\uparrow \uparrow$ & $\uparrow \uparrow$ \\
\hline
\end{tabular}

Table 1: Lifelong changes in the sex hormone levels of women and their correlations with insulin resistance, type-2 diabetes and obesity.

of hyperinsulinemia and hyperandrogenism reveal the early phase of metabolic and hormonal disturbances $[105,106]$.

PCOS is not only an infertility disease but also represents a high systemic health risk for the affected women. Increased levels of insulin and insulin like growth factors (IGFs) are directly related to the high risk of cardiovascular lesions in women with PCOS [107]. Moreover, the excessive ovarian androgen production and defective estrogen synthesis are strong risks for cardiovascular diseases as the gender dependent equilibrium of male to female sexual hormone level is the prerequisite of vascular health [4]. Atherosclerotic complications were directly related to hyperandrogenism in PCOS cases [107].

Increased prevalence of type 2 diabetes, hypertension and cardiovascular complications were observed in a follow up study of a Dutch population of women with PCOS [70]. Close associations between PCOS and premature coronary and aortic atherosclerosis were revealed in middle-aged women $[108,109]$. A retrospective Swedish study found a 7.4-fold risk of myocardial infarction among women suffering of PCOS [110].

In young infertile, nulliparous women with or without PCOS, an elevated risk for endometrial cancer was observed [111]. The high prevalence of endometrial cancer is frequently associated with synchronous primary cancers of the ovary or breast $[111,112]$. This female organ triad has the highest estrogen demand showing peculiar cancer risk even in a slightly estrogen deficient environment $[7,16,113]$.

Earlier, some authors presumed that elevated estrogen levels unopposed by progestin continuously stimulate estrogen receptors in women with PCOS. This postulation explained the high risk of endometrial and breast cancers observed in these cases based on the concept of the carcinogenic capacity of estrogen [114]. Recently, insulin resistance and hyperinsulinemia in PCOS patients are regarded as concomitants of high ovarian and adrenal androgen synthesis at the expense of defective estrogen production $[16,115]$.

Hyperprolactinemia is also associated with insulin resistance, obesity, cycle disorders, reproductive dysfunction and hyperandrogenism in women. Glucose intolerance and obesity are characteristic in hyperprolactinemia, suggesting that the associated hormonal disturbances might also be modulators of insulin sensitivity and body weight $[116,117]$. In a population based cohort study the overall cancer risk was elevated in patients with hyperprolactinemia [118].
Oral contraceptive (OC) use replaces the natural menstrual cycle with relatively steady levels and fluctuations of artificial sex hormones. In PCOS cases, hormone treatment by oral contraceptives reduces the volume of cystic ovaries, decreases testosterone secretion and improves the carbohydrate and lipid metabolism as well [119]. Conversely, administration of the insulin sensitizing metformin in PCOS cases primarily lowers the high insulin level and at the same time improves menstrual abnormalities, ovulatory dysfunction and hirsutism [120].

Epidemiologic studies have confirmed that combined oral contraceptives provide substantial protection against endometrial and ovarian cancers in endangered anovulatory women [120]. A recent patent disclosed a method for treating hyperandrogenic states, including PCOS by an estrogen derivative compound, which is more advantageous against the dangerous dysmetabolism of PCOS cases than oral contraceptive administration [121].

Tamoxifen is a nonsteroidal anti-estrogenic drug used for adjuvant therapy of breast cancer and recently as a chemopreventive agent for breast cancer and for other cancers as well [122]. Nevertheless, worldwide administration of antiestrogen compounds yielded thorough disappointment [123].

Antiestrogens are cytostatic agents blocking the most important regulatory mechanisms associated with estrogen signaling. They have ambiguous impacts on mammary tumor development, however, the estrogen deprivation induces several life-threatening sideeffects and exhibits strong carcinogenic capacity, particularly in the highly estrogen dependent endometrium [124]. Results of casecontrol studies demonstrated an increased prevalence of fatty liver, intraabdominal fat accumulation and type 2 diabetes in breast cancer cases receiving tamoxifen $[122,125,126]$. Artificial blocking of estrogen signaling pathways seems to confer serious insulin resistance leading to metabolic syndrome and type 2 diabetes. These disorders are well-known promoters of cancer initiation and progression affecting preferentially the endometrium $[127,128]$.

\section{Correlations between estrogen loss and the risk of increasing insulin resistance in postmenopausal women}

Menopause at 50-52 years of age means a sudden loss of ovarian estrogen synthesis and confers further decline in the circulating hormone level.

Postmenopausal women never using HRT are obviously insulin resistant and exhibit increasing inclination to the associated 
comorbidities. With ageing, every year after menopause is associated with continuous estrogen loss and parallel advancing insulin resistance [129]. For women aged 55-65 years, weight gain and obesity are their major health risks [130]. In postmenopausal women, deepening dysmetabolism, obesity and disturbance of male to female sexual steroid levels are associated with increased prevalence of metabolic syndrome, type 2 diabetes, cardiovascular disease and malignancies.

In HRT user postmenopausal cases, the protective effect of estrogen substitution may counteract to the developing insulin resistance and their metabolic and hormonal equilibrium becomes reminiscent to that of young women with preserved circulatory estrogen levels [16]. Estradiol administration increases insulin sensitivity [6], yields favorable changes in plasma lipid levels [131] and its anti-obesity effect decreases fat-accumulation, particularly in visceral location [132,133]. All these impacts justify that HRT use is beneficially protective against insulin resistance and its comorbidities in postmenopausal women.

Hysterectomy and bilateral oophorectomy mean an abrupt, shocking hormone deprivation as compared with natural menopause. These patients are highly endangered as they have no possibility for gradual adaptation to estrogen loss by a compensatory hormone synthesis of the peripheral tissues $[89,113]$. Bilateral oophorectomy is used as a risk reduction strategy in BRCA1/2 mutation carriers, although data on long-term side effects are not yet available. In the US population, oophorectomy, particularly at a young age, has been associated with highly increased overall and cardiovascular disease mortality [134].

In 2011, the WHI Randomized Controlled Trial substantiated that estrogen treatment in women with prior hysterectomy resulted in a significantly lower breast cancer risk than in untreated controls [135137]. Hysterectomy seems to be a near uniformly high breast cancer risk for women, thus HRT studies on these homogenously selected cases proved to be methodologically strong and yielded unexpectedly correct results [7].

In postmenopausal women, antiestrogen administration is a worldwide practice as either therapeutic or cancer preventive agent. Both ER-blocker and aromatase inhibitor types of antiestrogens further aggravate the estrogen deficiency and insulin resistance of aged female patients [123].

\section{Conclusion}

Correlations between estrogen signaling and human morbidity seems to be very unclear and difficult topic. Nowadays, the opinions of scientists have been partially changed regarding "estrogen induced diseases" however; the overwhelming literary data are still contradictory.

Individual and population specific ER associated gene polymorphisms were presumed to illuminate the highly controversial clinical and experimental results on the role of estrogens in health and disease. Nevertheless, the puzzling biology behind estrogen action was not reassuringly clarified by studies on either disabled ERKO animals or patients with genotyping of their ERs.

Diverse disorders associated with insulin resistance are usually well treatable by estradiol substitution both in pre- and postmenopausal women as well as in animal experiments. ERs seem to have balanced interplay in the maintenance of ideal glucose uptake and energy expenditure with continuous adaptation to the momentarily changing intra and extracellular stimuli. This equilibrium may be shattered in case of a defective estrogen supply or by the derangement of ER signaling pathways.

Recently, new therapeutic options are planned based on the development of tissue specific selective estrogen receptor modulators (SERMs) by the pharmaceutical industry. Nevertheless, considering the beneficial results of estradiol substitution in diverse diseases, we should understand the marvelous network of ER signal transduction pathways instead of trying to manipulate it.

\section{References}

1. Reaven GM (1988) Banting lecture 1988. Role of insulin resistance in human disease. Diabetes 37: 1595-1607.

2. DeFronzo RA, Ferrannini E (1991) Insulin resistance. A multifaceted syndrome responsible for NIDDM, obesity, hypertension, dyslipidemia, and atherosclerotic cardiovascular disease. Diabetes Care 14: 173-194.

3. Björnström L, Sjöberg M (2005) Mechanisms of estrogen receptor signaling convergence of genomic and nongenomic actions on target genes. Mo Endocrinol 19: 833-842.

4. Reckelhoff JF (2005) Sex steroids, cardiovascular disease, and hypertension unanswered questions and some speculations. Hypertension 45: 170-174.

5. Suba Zs (2013) Estrogen deficiency as cancer risk factor. In: Suba Zs Ed Estrogen versus Cancer 5: 85-106.

6. Barros RP, Machado UF, Gustafsson JA (2006) Estrogen receptors: new players in diabetes mellitus. Trends Mol Med 12: 425-431.

7. Suba Z (2012) Interplay between insulin resistance and estrogen deficiency as co- activators in carcinogenesis. Pathol Oncol Res 18: 123-133.

8. Barros RP, Gustafsson JA (2011) Estrogen receptors and the metabolic network. Cell Metab 14: 289-299.

9. Garvey TL, Maianu JH, Zhu W, Hancock JA. Golichowski AM (1993) Multiple defects in the adipocyte glucose transport system cause cellular insulin resistance in gestational diabetes. Heterogeneity in the number and a nove abnormality in subcellular localization of GLUT4 glucose transporters. Diabetes 42: 1773-1785.

10. Okuno S, Akazawa S, Yasuhi I, Kawasaki E, Matsumoto K, et al. (1995) Decreased expression of the GLUT4 glucose transporter protein in adipose tissue during pregnancy. Horm Metab Res 27: 231-234.

11. Stubbins RE, Najjar K, Holcomb VB, Hong J, Núñez NP (2012) Oestrogen alters adipocyte biology and protects female mice from adipocyte inflammation and insulin resistance. Diabetes Obes Metab 14: 58-66.

12. Riant E, Waget A, Cogo H, Arnal JF, Burcelin R, et al. (2009) Estrogens protect against high-fat diet-induced insulin resistance and glucose intolerance in mice. Endocrinology 150: 2109-2117.

13. Deguchi J, Miyamoto M, Okada S (1995) Sex hormone-dependent renal cell carcinogenesis induced by ferric nitrilotriacetate in Wistar rats. Jpn J Cancer Res 86: 1068-1071.

14. Nkhata KJ, Ray A, Dogan S, Grande JP, Cleary MP (2009) Mammary tumo development from T47-D human breast cancer cells in obese ovariectomized mice with and without estradiol supplements. Breast Cancer Res Treat 114 71-83.

15. Hong J, Holcomb VB, Kushiro K, Núñez NP (2011) Estrogen inhibits the effects of obesity and alcohol on mammary tumors and fatty liver. Int J Oncol 39: 14431453.

16. Suba $Z$ (2013) Circulatory estrogen level protects against breast cancer in obese women. Recent Pat Anticancer Drug Discov 8: 154-167.

17. Enmark E, Pelto-Huikko M, Grandien K, Lagercrantz S, Lagercrantz J, et al. (1997) Human estrogen receptor beta-gene structure, chromosomal localization, and expression pattern. J Clin Endocrinol Metab 82: 4258-4265.

18. Nilsson S, Mäkelä S, Treuter E, Tujague M, Thomsen J, et al. (2001) Mechanisms of estrogen action. Physiol Rev 81: 1535-1565.

19. Segars JH, Driggers PH (2002) Estrogen action and cytoplasmic signaling cascades. Part I: membrane-associated signaling complexes. Trends Endocrinol Metab 13: 349-354. 
Citation: Suba Z (2013) Low Estrogen Exposure and/or Defective Estrogen Signaling Induces Disturbances in Glucose Uptake and Energy Expenditure. J Diabetes Metab 4: 272. doi:10.4172/2155-6156.1000272

Page 8 of 10

20. Lindberg MK, Movérare S, Skrtic S, Gao H, Dahlman-Wright K, et al. (2003) Estrogen receptor (ER)-beta reduces ERalpha-regulated gene transcription, supporting a "ying yang" relationship between ERalpha and ERbeta in mice. Mol Endocrinol 17: 203-208.

21. Helguero LA, Faulds MH, Gustafsson JA, Haldosén LA (2005) Estrogen receptors alfa (ERalpha) and beta (ERbeta) differentially regulate proliferation and apoptosis of the normal murine mammary epithelial cell line HC11. Oncogene 24: 6605-6616.

22. Heine PA, Taylor JA, Iwamoto GA, Lubahn DB, Cooke PS (2000) Increased adipose tissue in male and female estrogen receptor-alpha knockout mice. Proc Natl Acad Sci U S A 97: 12729-12734.

23. Naaz A, Zakroczymski M, Heine P, Taylor J, Saunders P, et al. (2002) Effect of ovariectomy on adipose tissue of mice in the absence of estrogen receptor alpha (ERalpha): a potential role for estrogen receptor beta (ERbeta). Horm Metab Res 34: 758-763.

24. Morton GJ, Cummings DE, Baskin DG, Barsh GS, Schwartz MW (2006) Central nervous system control of food intake and body weight. Nature 443: 289-295.

25. Roepke TA (2009) Oestrogen modulates hypothalamic control of energy homeostasis through multiple mechanisms. J Neuroendocrinol 21: 141-150.

26. Muschamp JW, Hull EM (2007) Melanin concentrating hormone and estrogen receptor-alpha are coexstensive but not coexpressed in cells of male rat hypothalamus. Neurosci Lett 427: 123-126.

27. Laflamme N, Nappi RE. Drolet G, Labrie C, Rivest S (1998) Expression and neuropeptidergic characterization of estrogen receptors (ERalpha and ERbeta) throughout the rat brain: anatomical evidence of distinct roles of each subtype. J Neurobiol 36: 357-378.

28. Xu B, Goulding EH, Zang K, Cepoi D, Cone RD, et al. (2003) Brain-derived neurotrophic factor regulates energy balance downstream of melanocortin-4 receptor. Nat Neurosci 6: 736-742.

29. Laudenslager ML, Wilkinson CW, Carlisle HJ, Hammel HT (1980) Energy balance in ovariectomized rats with and without estrogen replacement. $\mathrm{Am} \mathrm{J}$ Physiol 238: R400-405

30. Ahima RS, Bjorbaek C, Osei S, Flier JS (1999) Regulation of neuronal and glial proteins by leptin: implications for brain development. Endocrinology 140: 2755-2762.

31. Elias CF, Aschkenasi C, Lee C, Kelly J, Ahima RS, et al. (1999) Leptin differentially regulates NPY and POMC neurons projecting to the lateral hypothalamic area. Neuron 23: 775-786.

32. Machinal F, Dieudonne MN, Leneveu MC, Pecquery R, Giudicelli Y (1999) In vivo and in vitro ob gene expression and leptin secretion in rat adipocytes: evidence for a regional specific regulation by sex steroid hormones. Endocrinology 140: 1567-1574.

33. Ainslie DA, Morris MJ, Wittert G, Turnbull H, Proietto J, et al. (2001) Estrogen deficiency causes central leptin insensitivity and increased hypothalamic neuropeptide Y. Int J Obes Relat Metab Disord 25: 1680-1688.

34. Clegg DJ, Brown LM, Woods SC, Benoit SC (2006) Gonadal hormones determine sensitivity to central leptin and insulin. Diabetes 55: 978-987.

35. Thammacharoen S, Geary N, Lutz TA, Ogawa S, Asarian L (2009) Divergen effects of estradiol and the estrogen receptor-alpha agonist PPT on eating and activation of PVN CRH neurons in ovariectomized rats and mice. Brain Res 1268: 88-96.

36. Musatov S, Chen W, Pfaff DW, Mobbs CV, Yang XJ, et al. (2007) Silencing of estrogen receptor alpha in the ventromedial nucleus of hypothalamus leads to metabolic syndrome. Proc Natl Acad Sci U S A 104: 2501-2506.

37. Liang YQ, Akishita M, Kim S, Ako J, Hashimoto M, et al. (2002) Estrogen receptor beta is involved in the anorectic action of estrogen. Int J Obes Relat Metab Disord 26: 1103-1109.

38. Genabai NK, Briski KP (2010) Adaptation of arcuate insulin receptor, estrogen receptor-alpha, estrogen receptor-beta, and type-II glucocorticoid receptor gene profiles to chronic intermediate insulin-induced hypoglycemia in estrogentreated ovariectomized female rats. J Mol Neurosci 2010 41: 304-309.

39. Pallottini V, Bulzomi P, Galluzzo P, Martini C, Marino M (2008) Estrogen regulation of adipose tissue functions: involvement of estrogen receptor isoforms. Infect Disord Drug Targets 8: 52-60.

40. Choi SB, Jang JS, Park S (2005) Estrogen and exercise may enhance beta-cell function and mass via insulin receptor substrate 2 induction in ovariectomized diabetic rats. Endocrinology 146: 4786-4794.

41. Tiano JP, Mauvais-Jarvis F (2012) Importance of oestrogen receptors to preserve functional $\hat{I}^{2}$-cell mass in diabetes. Nat Rev Endocrinol 8: 342-351.

42. Godsland IF (2005) Oestrogens and insulin secretion. Diabetologia 48: 22132220.

43. Gao H, Fält S, Sandelin A, Gustafsson JA, Dahlman-Wright K (2008) Genomewide identification of estrogen receptor alpha-binding sites in mouse liver. Mol Endocrinol 22: 10-22.

44. Bryzgalova G, Gao H, Ahren B, Zierath JR, Galuska D, et al. (2006) Evidence that oestrogen receptor-alpha plays an important role in the regulation of glucose homeostasis in mice: insulin sensitivity in the liver. Diabetologia 49 588-597.

45. Lundholm L, Bryzgalova G, Gao H, Portwood N, Fält S, et al. (2008) The estrogen receptor alpha-selective agonist propyl pyrazole triol improves glucose tolerance in ob/ob mice; potential molecular mechanisms. J Endocrino 199: $275-286$.

46. Foryst-Ludwig A, Clemenz M, Hohmann S, Hartge M, Sprang C, et al. (2008) Metabolic actions of estrogen receptor beta (ERbeta) are mediated by a negative cross-talk with PPARgamma. PLoS Genet 4: e1000108.

47. Fernández-Pérez L, Guerra B, Díaz-Chico JC, Flores-Morales A (2013) Estrogens regulate the hepatic effects of growth hormone, a hormonal interplay with multiple fates. Front Endocrinol (Lausanne) 4: 66.

48. Leung KC, Johannsson G, Leong GM, Ho KK (2004) Estrogen regulation of growth hormone action. Endocr Rev 25: 693-721.

49. Mode A, Gustafsson JA (2006) Sex and the liver - a journey through five decades. Drug Metab Rev 38: 197-207.

50. Baik M, Yu JH, Hennighausen L (2011) Growth hormone-STAT5 regulation of growth, hepatocellular carcinoma, and liver metabolism. Ann N Y Acad Sci 1229: 29-37.

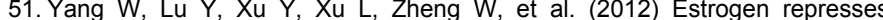
hepatocellular carcinoma (HCC) growth via inhibiting alternative activation of tumor-associated macrophages (TAMs). J Biol Chem 287: 40140-40149.

52. Evans MJ, Lai K, Shaw LJ, Harnish DC, Chadwick CC (2002) Estrogen receptor alpha inhibits IL-1beta induction of gene expression in the mouse liver. Endocrinology 143: 2559-2570.

53. Wang YC, Xu GL, Jia WD, Han SJ, Ren WH, et al. (2012) Estrogen suppresses metastasis in rat hepatocellular carcinoma through decreasing interleukin- 6 and hepatocyte growth factor expression.Inflammation 35: 143-149.

54. Espeland MA, Marcovina SM, Miller V, Wood PD, Wasilauskas C, et al. (1998) Effect of postmenopausal hormone therapy on lipoprotein(a) concentration. PEPI Investigators. Postmenopausal Estrogen/Progestin Interventions Circulation 97: 979-986.

55. Redig AJ, Munshi HG (2010) Care of the cancer survivor: metabolic syndrome after hormone-modifying therapy. Am J Med 123: 87

56. Kasuga M, Hedo JA, Yamada KM, Kahn CR (1982) The structure of insulin receptor and its subunits. Evidence for multiple nonreduced forms and a 210,000 possible proreceptor. J Biol Chem 257: 10392-10399.

57. Zhou L, Chen H, Xu P, Cong LN, Sciacchitano S, et al. (1999) Action of insulin receptor substrate-3 (IRS-3) and IRS-4 to stimulate translocation of GLUT4 in rat adipose cells. Mol Endocrinol 13: 505-514.

58. Rogers NH, Witczak CA, Hirshman MF, Goodyear LJ, Greenberg AS (2009) Estradiol stimulates Akt, AMP-activated protein kinase (AMPK) and TBC1D1/4, but not glucose uptake in rat soleus. Biochem Biophys Res Commun 382: 646650 .

59. Ordóñez P, Moreno M, Alonso A, Llaneza P, Díaz F, et al. (2008) 17betaEstradiol and/or progesterone protect from insulin resistance in STZ-induced diabetic rats. J Steroid Biochem Mol Biol 111: 287-294

60. Muraki K, Okuya S, Tanizawa Y (2006) Estrogen receptor alpha regulates insulin sensitivity through IRS-1 tyrosine phosphorylation in mature 3T3-L1 adipocytes. Endocr J 53: 841-851.

61. Moreno M, Ordoñez P, Alonso A, Díaz F, Tolivia J, et al. (2010) Chronic 17beta-estradiol treatment improves skeletal muscle insulin signaling pathway components in insulin resistance associated with aging. Age (Dordr) 32: 1-13. 
Citation: Suba Z (2013) Low Estrogen Exposure and/or Defective Estrogen Signaling Induces Disturbances in Glucose Uptake and Energy Expenditure. J Diabetes Metab 4: 272. doi:10.4172/2155-6156.1000272

62. Shi J, Simpkins JW (1997) 17 beta-Estradiol modulation of glucose transporter 1 expression in blood-brain barrier. Am J Physiol 272: E1016-1022.

63. Fisher CR, Graves KH, Parlow AF, Simpson ER (1998) Characterization of mice deficient in aromatase (ArKO) because of targeted disruption of the cyp19 gene. Proc Natl Acad Sci U S A 95: 6965-6970.

64. Jones ME, Thorburn AW, Britt KL, Hewitt KN, Wreford NG, et al. (2000) Aromatase-deficient (ArKO) mice have a phenotype of increased adiposity. Proc Natl Acad Sci U S A 97: 12735-12740.

65. Takeda K, Toda K, Saibara T, Nakagawa M, Saika K, et al. (2003) Progressive development of insulin resistance phenotype in male mice with complete aromatase (CYP19) deficiency. J Endocrinol 176: 237-246.

66. Galluzzo P, Rastelli C, Bulzomi P, Acconcia F, Pallottini V, et al. (2009) 17betaEstradiol regulates the first steps of skeletal muscle cell differentiation via ERalpha-mediated signals. Am J Physiol Cell Physiol 297: C1249-1262.

67. Phillips SK, Rook KM, Siddle NC, Bruce SA, Woledge RC (1993) Muscle weakness in women occurs at an earlier age than in men, but strength is preserved by hormone replacement therapy. Clin Sci (Lond) 84: 95-98.

68. Greising SM, Baltgalvis KA, Lowe DA, Warren GL (2009) Hormone therapy and skeletal muscle strength: a meta-analysis. J Gerontol A Biol Sci Med Sci 64: 1071-1081.

69. Livingstone C, Collison M (2002) Sex steroids and insulin resistance. Clin Sci (Lond) 102: 151-166.

70. Frayn KN, Karpe F, Fielding BA, Macdonald IA, Coppack SW (2003) Integrative physiology of human adipose tissue. Int J Obes Relat Metab Disord 27: 875-

71. Kim JY, Jo KJ, Kim OS, Kim BJ, Kang DW, et al. (2010) Parenteral 17betaestradiol decreases fasting blood glucose levels in non-obese mice with shortterm ovariectomy. Life Sci 87: 358-366.

72. Elting MW, Korsen TJ, Bezemer PD, Schoemaker J (2001) Prevalence of diabetes mellitus, hypertension and cardiac complaints in a follow-up study of a Dutch PCOS population. Hum Reprod 16: 556-560

73. Suba Zs (2009) Insulin resistance, estrogen deficiency and cancer risk.. In: Ed Suba Zs. Estrogen versus Cancer 7: 127-146.

74. Wohlers LM, Spangenburg EE (2010) 17beta-estradiol supplementation attenuates ovariectomy-induced increases in ATGL signaling and reduced perilipin expression in visceral adipose tissue. J Cell Biochem 110: 420-427.

75. Dieudonné MN, Leneveu MC, Giudicelli Y, Pecquery R (2004) Evidence for functional estrogen receptors alpha and beta in human adipose cells: regional specificities and regulation by estrogens. Am J Physiol Cell Physiol 286: C655661.

76. Smith EP, Boyd J, Frank GR, Takahashi H, Cohen RM, et al. (1994) Estrogen resistance caused by a mutation in the estrogen-receptor gene in a man. $\mathrm{N}$ Engl J Med 331: 1056-1061.

77. Sudhir K, Chou TM, Chatterjee K, Smith EP, Williams TC, et al. (1997) Premature coronary artery disease associated with a disruptive mutation in the estrogen receptor gene in a man. Circulation 96: 3774-3777.

78. Rosenbaum D, Haber RS, Dunaif A (1993) Insulin resistance in polycystic ovary syndrome: decreased expression of GLUT-4 glucose transporters in adipocytes. Am J Physiol 264: E197-202.

79. Austad SN (2006) Why women live longer than men: sex differences in longevity. Gend Med 3: 79-92.

80. Suba $Z$ (2009) The role of estrogen in health and disease. In: Ed. Suba $Z$. Estrogen versus Cancer 4: 59-84

81. Rossouw JE, Anderson GL, Prentice RL, LaCroix AZ, Kooperberg C, et al. (2002) Risks and benefits of estrogen plus progestin in healthy postmenopausal women: principal results from the Women's Health Initiative randomized controlled trial. JAMA 288: 321-333.

82. Newton-Cheh C, O’Donnell CJ (2004) Sex differences and genetic associations with myocardial infarction. JAMA 291: 3008-3010.

83. Shearman AM, Cupples LA, Demissie S, Peter I, Schmid CH, et al. (2003) Association between estrogen receptor alpha gene variation and cardiovascular disease. JAMA 290: 2263-2270.

84. Schuit SC, Oei HH, Witteman JC, Geurts van Kessel CH, van Meurs JB, et al.
(2004) Estrogen receptor alpha gene polymorphisms and risk of myocardial infarction. JAMA 291: 2969-2977.

85. Ferrero V, Ribichini F, Matullo G, Guarrera S, Carturan S, et al. (2003) Estrogen receptor-alpha polymorphisms and angiographic outcome after coronary artery stenting. Arterioscler Thromb Vasc Biol 23: 2223-2228.

86. Koivu TA, Fan YM, Mattila KM, Dastidar P, Jokela H, et al. (2003) The effect of hormone replacement therapy on atherosclerotic severity in relation to ESR1 genotype in postmenopausal women. Maturitas 44: 29-38.

87. Nordström P, Glader CA, Dahlén G, Birgander LS, Lorentzon R, et al. (2003) Oestrogen receptor alpha gene polymorphism is related to aortic valve sclerosis in postmenopausal women. J Intern Med 254: 140-146.

88. Hu J, Wang J, Xiang H, Li Z, Wang B, et al. (2012) Association of polymorphisms in the estrogen receptor $\hat{i}^{2}$ (ESR2) with unexplained recurrent spontaneous abortion (URSA) in Chinese population. J Matern Fetal Neonatal Med 25: 17271729.

89. Cai Q, Shu XO, Jin F, Dai Q, Wen W, et al. (2003) Genetic polymorphisms in the estrogen receptor alpha gene and risk of breast cancer: results from the Shanghai Breast Cancer Study.Cancer Epidemiol Biomarkers Prev 12: 853 859 .

90. Shin A, Kang D, Nishio H, Lee MJ, Park SK, et al. (2003) Estrogen receptor alpha gene polymorphisms and breast cancer risk. Breast Cancer Res Treat 80: 127-131.

91. Suba Z (2010) Common soil of smoking-associated and hormone-related cancers: estrogen deficiency. Oncol Rev 4: 73-87.

92. Matsuzaka Y, Kikuti YY, Izumi S, Goya K, Suzuki T, et al. (2012) Failure to detect significant association between estrogen receptor-alpha gene polymorphisms and endometriosis in Japanese women.Environ Health Prev Med 17: 423-428.

93. Li Y, Low HQ, Foo JN, Darabi H, Einarsdottir K, et al. (2012) Genetic variants in ER cofactor genes and endometrial cancer risk. PLoS One 7: e42445.

94. Weiderpass E, Persson I, Melhus H, Wedrén S, Kindmark A, et al. (2000) Estrogen receptor alpha gene polymorphisms and endometrial cancer risk. Carcinogenesis 21: 623-627.

95. Nectaria X, Leandros L, loannis G, Agathocles T (2012) The importance of ER $\alpha$ and ER $\beta$ gene polymorphisms in PCOS. Gynecol Endocrinol 28 505-508.

96. Ryan J, Canonico M, Carcaillon L, Carrière I, Scali J, et al. (2012) Hormone treatment, estrogen receptor polymorphisms and mortality: a prospective cohort study. PLoS One 7: e34112.

97. Suba Z (2012) Light deficiency confers breast cancer risk by endocrine disorders. Recent Pat Anticancer Drug Discov 7: 337-344.

98. Stoll BA (1998) Teenage obesity in relation to breast cancer risk. Int J Obes Relat Metab Disord 22: 1035-1040.

99. Apter D, Vihko R (1990) Endocrine determinants of fertility: serum androgen concentrations during follow-up of adolescents into the third decade of life. Clin Endocrinol Metab 71: 970-974

100.Baer HJ, Colditz GA, Willett WC, Dorgan JF (2007) Adiposity and sex hormones in girls. Cancer Epidemiol Biomarkers Prev 16: 1880-1888.

101. Theintz G (2005) From obesity to type 2 diabetes in children and adolescents Rev Med Suisse 1: 477-480.

102. Vanhala MJ, Vanhala PT, Keinänen-Kiukaanniemi SM, Kumpusalo EA Takala JK (1999) Relative weight gain and obesity as a child predict metabolic syndrome as an adult. Int J Obes Relat Metab Disord 23: 656-659.

103. Lewy VD, Danadian K, Witchel SF, Arslanian S (2001) Early metabolic abnormalities in adolescent girls with polycystic ovarian syndrome. J Pediatr 138: $38-44$

104.Zain MM, Norman RJ (2008) Impact of obesity on female fertility and fertility treatment. Womens Health (Lond Engl) 4: 183-194.

105. Rose DP, Vona-Davis L (2010) Interaction between menopausal status and obesity in affecting breast cancer risk. Maturitas 66: 33-38.

106. Bloomgarden ZT (2005) Second World Congress on the Insulin Resistance Syndrome: mediators, pediatric insulin resistance, the polycystic ovary syndrome, and malignancy. Diabetes Care 28: 1821-1830.

107. Polson DW, Adams J, Wadsworth J, Franks S (1988) Polycystic ovaries--a common finding in normal women. Lancet 1: 870-872. 
Citation: Suba Z (2013) Low Estrogen Exposure and/or Defective Estrogen Signaling Induces Disturbances in Glucose Uptake and Energy Expenditure. J Diabetes Metab 4: 272. doi:10.4172/2155-6156.1000272

108. Carmina E, Lobo RA (2001) Polycystic ovaries in Hirsute women with normal menses. Am J Med 111: 602-606.

109. Christakou CD, Diamanti-Kandarakis E (2008) Role of androgen excess on metabolic aberrations and cardiovascular risk in women with polycystic ovary syndrome. Womens Health (Lond Engl) 4: 583-594.

110. Talbott E, Guzick D, Clerici A, Berga S, Detre K, et al. (1995) Coronary heart disease risk factors in women with polycystic ovary syndrome. Arterioscler Thromb Vasc Biol 15: 821-826.

111. Talbott EO, Zborowski JV, Rager JR, Boudreaux MY, Edmundowicz DA, et al. (2004) Evidence for an association between metabolic cardiovascular syndrome and coronary and aortic calcification among women with polycystic ovary syndrome. J Clin Endocrinol Metab 89: 5454-5461.

112. Dahlgren E, Johansson S, Lindstedt G, Knutsson F, Odén A, et al. (1992) Women with polycystic ovary syndrome wedge resected in 1956 to 1965: a long-term follow-up focusing on natural history and circulating hormones. Fertil Steril 57: 505-513.

113. Soliman PT, Oh JC, Schmeler KM, Sun CC, Slomovitz BM, et al. (2005) Risk factors for young premenopausal women with endometrial cancer. Obste Gynecol 105: 575-580

114. Uccella S, Cha SS, Melton LJ 3rd, Bergstralh EJ, Boardman LA, et al. (2011) Risk factors for developing multiple malignancies in patients with endometrial cancer. Int J Gynecol Cancer 21: 896-901.

115. Suba ZS (2013) Discovery of estrogen deficiency as common cancer risk factor for highly and moderately estrogen dependent organs. In: Suba ZS (Ed.) Estrogen prevention for breast cancer 1: 1-22.

116. Gadducci A, Gargini A, Palla E, Fanucchi A, Genazzani AR (2005) Polycystic ovary syndrome and gynecological cancers: is there a link? Gynecol Endocrinol 20: 200-208.

117. Nestler JE (2000) Obesity, insulin, sex steroids and ovulation. Int J Obes Relat Metab Disord 24: S71-73.

118. Tuzcu A, Yalaki S, Arikan S, Gokalp D, Bahcec M, et al. (2009) Evaluation of insulin sensitivity in hyperprolactinemic subjects by euglycemic hyperinsulinemic clamp technique. Pituitary 12: 330-334.

119. Shibli-Rahhal A, Schlechte J (2009) The effects of hyperprolactinemia on bone and fat. Pituitary 12: 96-104

120.Berinder K, Akre O, Granath F, Hulting AL (2011) Cancer risk in hyperprolactinemia patients: a population-based cohort study. Eur J Endocrinol 165: 209-215.

121. ESHRE Capri Workshop Group (2001) Ovarian and endometrial function during hormonal contraception. Hum Reprod 16: 1527-1535.

122. Deligeoroglou E, Michailidis E, Creatsas G (2003) Oral contraceptives and reproductive system cancer. Ann N Y Acad Sci 997: 199-208.
123. Tejura B (2010) Methods of treating hyperandrogenism and conditions associated therewith by administering a fatty acid ester of an estrogen or an estrogen derivative. US20100286105.

124. Nguyen MC, Stewart RB, Banerji MA, Gordon DH, Kral JG (2001) Relationships between tamoxifen use, liver fat and body fat distribution in women with breas cancer. Int J Obes Relat Metab Disord 25: 296-298.

125. Suba Z (2011) Antiestrogen or estrogen as anticancer drug. In:Hoffmann AB Ed. Sex hormones: development, regulation and disorders 4: 75-94.

126. Suba $Z$ (2013) Failures and controversies of the antiestrogen treatment of breast cancer. In: Suba Z. Ed. Estrogen prevention for breast cancer 6: 105125.

127. Saphner T, Triest-Robertson S, Li H, Holzman P (2009) The association of nonalcoholic steatohepatitis and tamoxifen in patients with breast cancer. Cancer 115: 3189-3195.

128. Lipscombe LL, Fischer HD, Yun L, Gruneir A, Austin P, et al. (2012) Association between tamoxifen treatment and diabetes: a population-based study. Cancer 118: $2615-2622$.

129. Burzawa JK, Schmeler KM, Soliman PT, Meyer LA, Bevers MW, et al. (2011) Prospective evaluation of insulin resistance among endometrial cancer patients. Am J Obstet Gynecol 204: 355.

130. Friedenreich CM, Biel RK, Lau DC, Csizmadi I, Courneya KS, et al. (2011) Case-control study of the metabolic syndrome and metabolic risk factors for endometrial cancer. Cancer Epidemiol Biomarkers Prev 20: 2384-2395.

131.Schneider JG, Tompkins C, Blumenthal RS, Mora S (2006) The metabolic syndrome in women. Cardiol Rev 14: 286-291.

132.Davis SR, Castelo-Branco C, Chedraui P, Lumsden MA, Nappi RE, et al. (2012) Understanding weight gain at menopause. Climacteric 15: 419-429.

133. Walsh BW, Schiff I, Rosner B, Greenberg L, Ravnikar V, et al. (1991) Effects of postmenopausal estrogen replacement on the concentrations and metabolism of plasma lipoproteins. N Engl J Med 325: 1196-1204.

134. Gunter MJ, Hoover DR, Yu H, Wassertheil-Smoller S, Rohan TE, et al. (2009) Insulin, insulin-like growth factor-I, and risk of breast cancer in postmenopausal women. J Natl Cancer Inst 101: 48-60.

135. Tchernof A, Calles-Escandon J, Sites CK, Poehlman ET (1998) Menopause central body fatness, and insulin resistance: effects of hormone-replacement therapy. Coron Artery Dis 9: 503-511.

136. McCarthy AM, Menke A, Ouyang P, Visvanathan K (2012) Bilateral oophorectomy, body mass index, and mortality in U.S. women aged 40 years and older. Cancer Prev Res (Phila) 5: 847-854.

137. LaCroix AZ, Chlebowski RT, Manson JE, Aragaki AK, Johnson KC, et al. (2011) Health outcomes after stopping conjugated equine estrogens among postmenopausal women with prior hysterectomy. A randomized controlled trial. JAMA 305: 1305-1314. 